\title{
Arqueología, etnografía y el contexto artístico en Brasil en el Segundo Reinado: las obras de los escultores Ferdinand Pettrich y Louis Rochet
}

Archaeology, ethnography and the artistic context in Brazil during the Second Empire: the works of the sculptors Ferdinand Pettrich and Louis Rochet

\author{
Luciano Migliaccio \\ Universidade de São Paulo. São Paulo, São Paulo, Brasil
}

\begin{abstract}
Resumen: Siguiendo el trabajo anterior sobre la Expedición Científica de Exploración de la Sección de Arqueología y Etnografía del Instituto Histórico e Geográfico Brasileño, en ese texto será evidenciada la relación entre la ilustración etnográfica y la producción artística promovida por la corte del emperador Don Pedro Il y por el Academia Imperial de Bellas Artes de Rio de Janeiro. En particular, serán tratados dos casos: las esculturas figurando indios norte-americanos ejecutadas por el alemán Ferdinand Pettrich en Estados Unidos entre 1835 y 1845, re-elaboradas durante la estada brasileña del artista hasta 1857 y donadas al papa Pio IX, hoy en el Museo Etnologico Missionario en Ciudad del Vaticano. El caso más relevante para nuestro análisis, sin embargo, es el del monumento ecuestre de Don Pedro I realizado por el escultor francés Louis Rochet en Rio de Janeiro entre 1857 y 1862, en que la ilustración etnográfica se une con intenciones conmemorativas y soluciones estéticas de fuerte impacto para el arte de la época.
\end{abstract}

Palabras-clave: Arqueología. Etnografía. Arte. Brasil. Século XIX.

Abstract: Following previous work about the Scientific Expedition of the Section of Archaeology and Ethnography of Brazilian Geographic and Historical Institute, it will be featured in this paper the relationship between ethnographic illustration and artistic production promoted by the court of Emperor Don Pedro II and Academia Imperial de Belas Artes in Rio de Janeiro. In particular, two cases will be discussed: the sculptures representing North American Indians executed by the German artist Ferdinand Pettrich in United States between 1835 and 1845, reworked during his Brazilian sojourn until 1857 and donated to Pope Pius IX which are now in the Museo Etnologico Missionario in Vatican City. Most relevant to our analysis, however, is the case of the equestrian monument of the Emperor Don Pedro I executed by French sculptor Louis Rochet in Rio de Janeiro between 1857 and 1862, in which the ethnographic illustration was mixed with epic intentions and aesthetic solutions which had strong impact on the art of the period.

Keywords: Archaelogy. Etnography. Art. Brazil. XIXth Century.

MIGLIACCIO, Luciano. Arqueología, etnografía y el contexto artístico en Brasil en el Segundo Reinado: las obras de los escultores Ferdinand Pettrich y Louis Rochet. Boletim do Museu Paraense Emílio Goeldi. Ciências Humanas, v. 12, n. 2, p. 389-401, maio-ago. 2017. DOI: http://dx.doi.org/10.1590/1981.81222017000200008.

Autor para correspondência: Luciano Migliaccio. Universidade de São Paulo. Faculdade de Arquitetura e Urbanismo. Rua do Lago, 876 - Cidade Universitária. São Paulo, SP, Brasil. CEP 05508-080 (migliac@usp.br).

Recebido em 13/04/2014

Aprovado em 10/03/2017

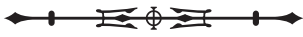


El poeta brasileño Antônio Gonçalves Dias publicó el poema épico indianista, "Os Timbiras", en 1857, en Leipzig (Dias, 1857). El año siguiente publicaría en la misma ciudad por la misma editora Brockhaus, su "Diccionario da lingua Tupy, chamada Lingua Geral dos indigenas do Brazil" (Dias, 1858). La publicación de las obras en el centro principal de la lingüística comparativa alemana, quizá intermediada por el historiador Varnhagen, puede ser el indicio de una relación entre la perspectiva de los estudios sobre la etnografía histórica de las poblaciones indígenas del Brasil y las hipótesis que lingüistas alemanes, como Franz Bopp e Fredrich Schlegel habían elaborado, a partir del estudio de los textos sánscritos, sobre la origen y las migraciones de los pueblos indo-europeos. Franz Bopp acabó de publicar su monumental gramática comparada de las lenguas indoeuropeas en 1852 (Bopp, 1833-1852). Tales teorías se desarrollaron en los centros universitarios alemanes, en particular en Leipzig y en Berlin, mas tenían su origen en París, donde Franz Bopp y Fredrich Schlegel habían sido alumnos de los cursos de sánscrito de Alexander Hamilton, y seguían despertando profundo interés entre los años veinte $y$ cuarenta del siglo XIX, gracias al trabajo de estudiosos como Louis-Mathieu Langlés y Eugéne Bournouf. En París, en el círculo del Institut Historique de Paris, entre 1831 y 1837, introducidos por Ferdinand Denis, Secretario Perpetuo del Instituto, formaron su pensamiento algunos de los más importantes miembros del Instituto Histórico e Geográfico Brasileiro (IHGB), a saber, Manuel de Araújo Porto-Alegre, Manuel Gonçalves Magalhães, Francisco Freire Alemão y Francisco de Sales Torres Homem (Pinassi, 1998). La metodología adoptada en el instituto francés fue el ejemplo sobre que se moldaron las investigaciones del recién nacido IHGB en particular al abordar el campo de la historia, de la arqueología y de la etnografía brasileñas.

El objetivo de ese artículo es indicar posibles relaciones entre este contexto de ideas que guiaran la acción de la Sección de Arqueología y Etnografía del
IHGB, presidida por Gonçalves Dias y la elaboración en los mismos años de algunas obras de arte de tema indianista en Brasil. Se trata de un conjunto de esculturas ejecutado por el artista alemán Ferdinand August Pettrich, hoy en el Museo Etnológico Misionario en Ciudad del Vaticano, y del monumento ecuestre de Dom Pedro I, emperador de Brasil, en Rio de Janeiro, realizado por el escultor francés Louis Rochet.

\section{LAS ESCULTURAS ETNOGRÁFICAS DE FERDINAND AUGUST PETTRICH}

Las obras de Pettrich representan en realidad figuras de indios norteamericanos, fueron empezadas durante la estada del artista alemán en Estados Unidos, de 1835 a 1845, y terminadas, como es dicho en un documento italiano, "nella quiete di una villa brasiliana", en la paz de una estancia brasileña (Dalla Torre, 1940, p. 86).

Pocos artistas tuvieron una vida tan agitada por cambios e viajes como el escultor alemán Ferdinand August Pettrich (Bugatto, 1931; Geller, 1955). Nació en Dresden, en Sajonia, en 3 de diciembre de 1798. Su padre, Franz Johann, también escultor, fue alumno del veneciano Francesco Giuseppe Casanova, artista de corte del Elector de Sajonia, Federico Augusto I, y pasó unas temporadas en Roma de 1802 a 1805, en el taller de Antonio Canova, junto con Bertel Thorvaldsen, destacándose en su patria por su adhesión al neoclasicismo severo del maestro dinamarqués. Ferdinand fue alumno de su padre y en abril de 1819 viajó a Roma con el príncipe António de Sajonia. Allí, Ferdinand acudió al taller de Thorvaldsen en la Accademia di San Luca y entró en el activo círculo de los jóvenes artistas alemanes, como atesta su colaboración en 1821 en la revista Akten der Bibliotek der Deutschen zu Rom (Noack, 1927, p. 385). A partir de 1822 fue asociado de la Venerabile Arciconfraternita del Camposanto Teutonico, tradicional hermandad de los católicos alemanes y finalmente en 1829 fue entre los primeros miembros de la Società Artística Romana, gremio de artistas alemanes que se 
reunía en Villa Malta'. El lugar destacado del escultor en la comunidad alemana de Roma fue confirmado cuando Martin Wagner, incumbido por el rey de Bavaria, Ludwig I, de curar la realización del friso externo de mármol del Walhalla, monumento conmemorativo de los ilustres alemanes y de los caídos en las guerras napoleónicas, construido por Leo von Klenz, em Regensburg, elijó por su colaboradores a Pettrich y al bávaro Peter Schoepf. Pettrich trabajó hasta 1834 en el friso dese gran templo, representando la historia de los antiguos Germanos desde su migración del Cáucaso hacia el Danubio hasta su evangelización. El programa iconográfico de esos bajorrelieves, posiblemente inspirado en teorías sobre la migración de los pueblos, oriundas de la lingüística comparativa, puede haber estimulado el interés de Pettrich en la vida de los Alemanes primitivos, en una perspectiva influenciada por pensadores románticos como Johann Herder y los hermanos Grimm, Jacob y Wilhelm (Avrilon, 2010).

Persuadido por Thorvaldsen, que lo estimularía a dedicarse al estudio de los tipos y de las fisionomías originales de los indios de América, antes de su desaparecimiento, para abrir nuevos caminos a la escultura, pero también para contribuir a los estudios de la etnografía y de la historia de las migraciones de los pueblos nativos americanos, Pettrich aceptó una invitación del gobierno estadounidense, y junto a su numerosa familia, viajó a Estados Unidos para poner en obra algunas esculturas del maestro. Aportó allá en diciembre de 1835 y fijó su residencia en Washington, relacionándose con personalidades influyentes de la política como Martin Van Buren, William Henry Harrison, Henry Clay, Andrew Jackson y John Tyler. Dentro de muchas obras ejecutadas en la capital de Estados Unidos, cabe citar los relieves para la base de la estatua de Washington, obra de Greenough, los retratos de los presidentes Tyler y Jackson, el monumento de Washington encomendado por la Smithsonian Institution, y la famosa estatua de Tecumseh herido, una de las primeras representaciones monumentales en escultura de indios americanos.

Sin embargo, el interés en relación a la representación etnográfica de los nativos no fue algo ocasional en la obra de Pettrich. De 1835 a 1842, en varias ocasiones, comparecieron en Washington representantes de diversas tribus indias para negociar con el Congreso de Estados Unidos condiciones de paz y cesiones de tierras. Pettrich tuvo la oportunidad de ejecutar retratos de jefes, guerreros, mujeres, y cenas de la vida de las tribus Sauks-Foxes, Sioux, Winnebago y Creek $^{2}$ (Figuras 1-4). A motivo de enemistades políticas, y de un atentado quizás organizado por partidarios de John Quincy Adams, enemigo del presidente John Tyler, protector del artista, Pettrich decidió huirse a Brasil. Las recomendaciones de Tyler, los cuidados del jefe de la delegación diplomática de Estados Unidos, William Hunter, y la amistad del cónsul general napolitano Gennaro Merolla, le proporcionaran el favor de Dom Pedro II, de su ministro y jefe de la Masonería brasileña José Clemente Pereira y de otras figuras importantes. En Brasil, además de ejecutar numerosas obras, Pettrich se dedicó a realizar las maquetas de yeso patinado en color rojo terracota, de la medida del natural, de las esculturas y de los relieves representando indios norteamericanos. El uso de pátina colorida y el método de trabajo de Pettrich para esas esculturas parecen introducir elementos profundamente originales en relación al clasicismo de Thorvaldsen.

\footnotetext{
La Villa Malta o Casina delle Rose en el Pincio, cerca de Villa Borghese, fue residencia de muchos aristócratas y intelectuales alemanes durante su temporada en Roma. Allí estuvieron Johann Wolfgang von Goethe, la duquesa Amalia de Braunschweig que hospedó a Herder, la poetisa Federica Brun. Esta transformó la villa en un importante círculo de intelectuales y viajeros de que formaron parte Luciano Bonaparte, Alexander von Humboldt, los pintores Vincenzo Camuccini y Joseph Anton Koch, los escultores Johann Gottfried Schadow, Antonio Canova y Bertel Thorvaldsen, el arqueólogo Jørgen Zoega y el futuro rey Ludwig de Bavaria. Desde 1810 fue referencia para los artistas del grupo de los Nazarenos.

2 La colección de esculturas de Pettrich en el Museo Etnologico Missionario del Vaticano es formada por 33 piezas: 4 bajorrelieves, 4 estatuas al natural, 16 bustos retratos, y 9 esbocetos.
}

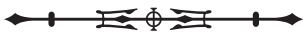




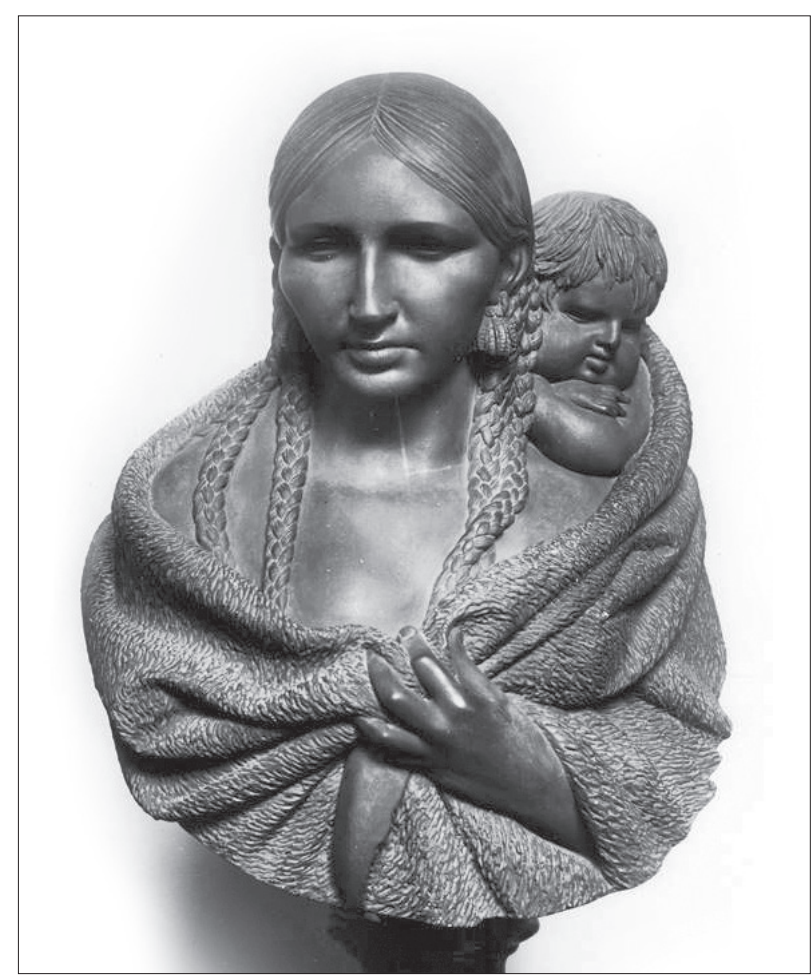

Figura 1. Ferdinand August Pettrich, Mujer de la tribu Sauks-Foxes, yeso patinado, Vaticano, Pontificio Museo Missionario-Etnologico. Foto: Luciano Migliaccio.

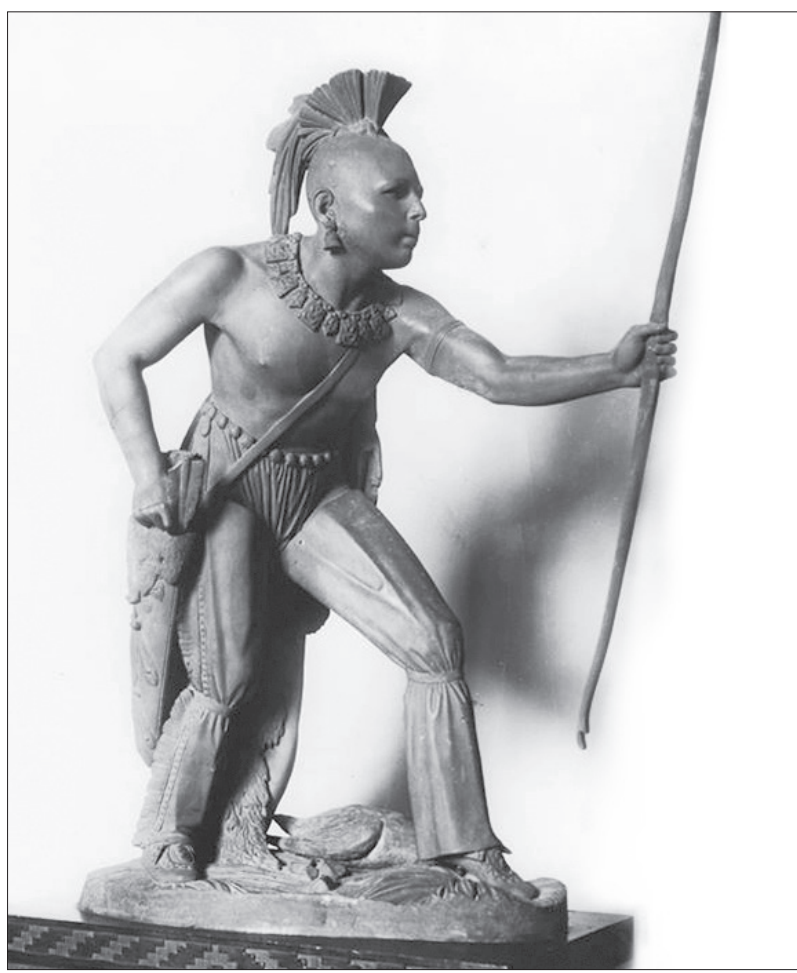

Figura 3. Ferdinand August Pettrich, Joven guerrero de la tribu Sauks-Foxes, yeso patinado, Vaticano, Pontificio Museo MissionarioEtnologico. Foto: Luciano Migliaccio.

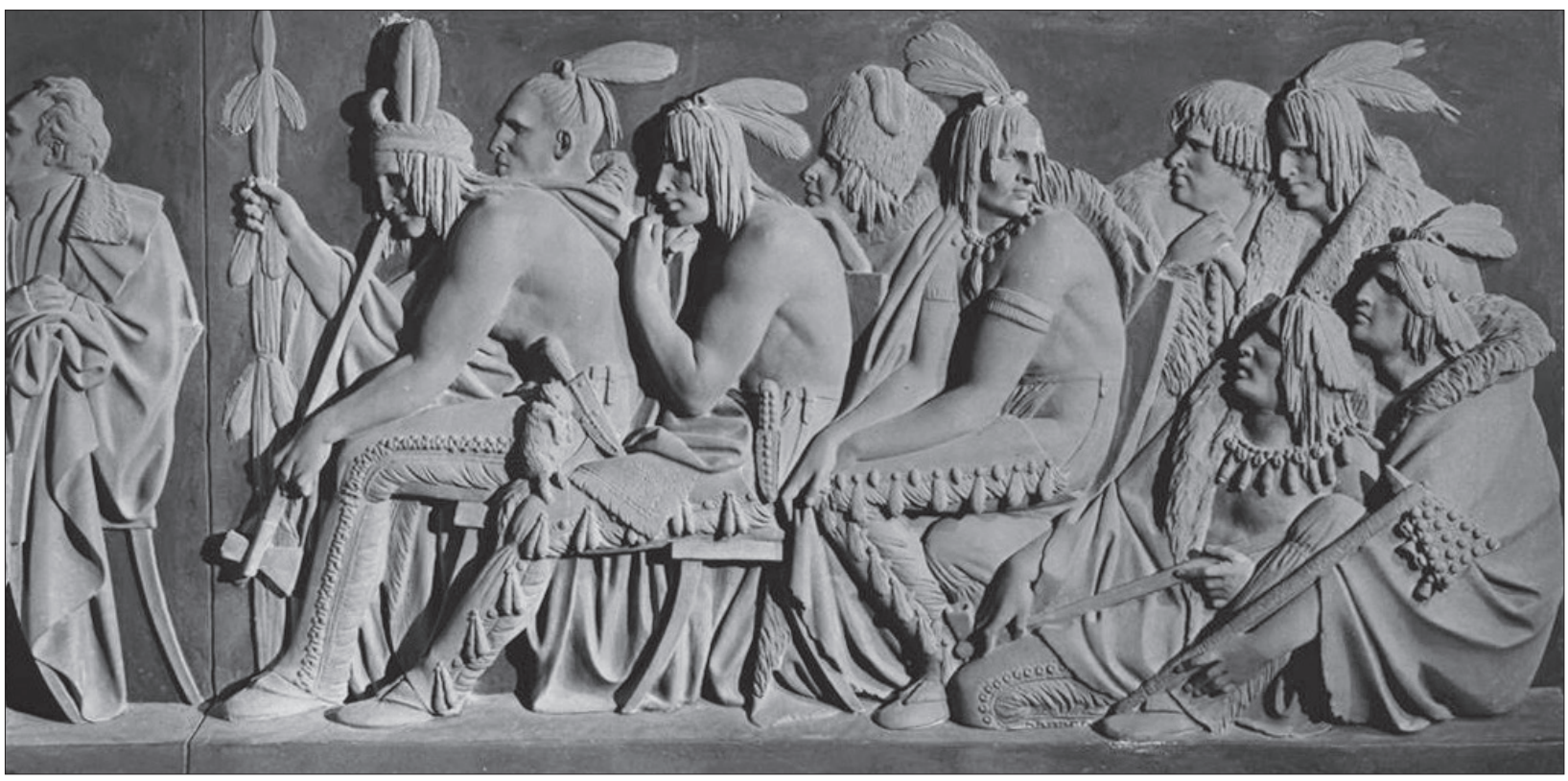

Figura 2. Ferdinand August Pettrich, Indios de la tribu Sauks-Foxes durante negociaciones con el gobierno estadounidense en Washington, bajorrelieve en yeso patinado, Vaticano, Pontificio Museo Missionario-Etnologico. Foto: Luciano Migliaccio.

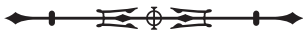




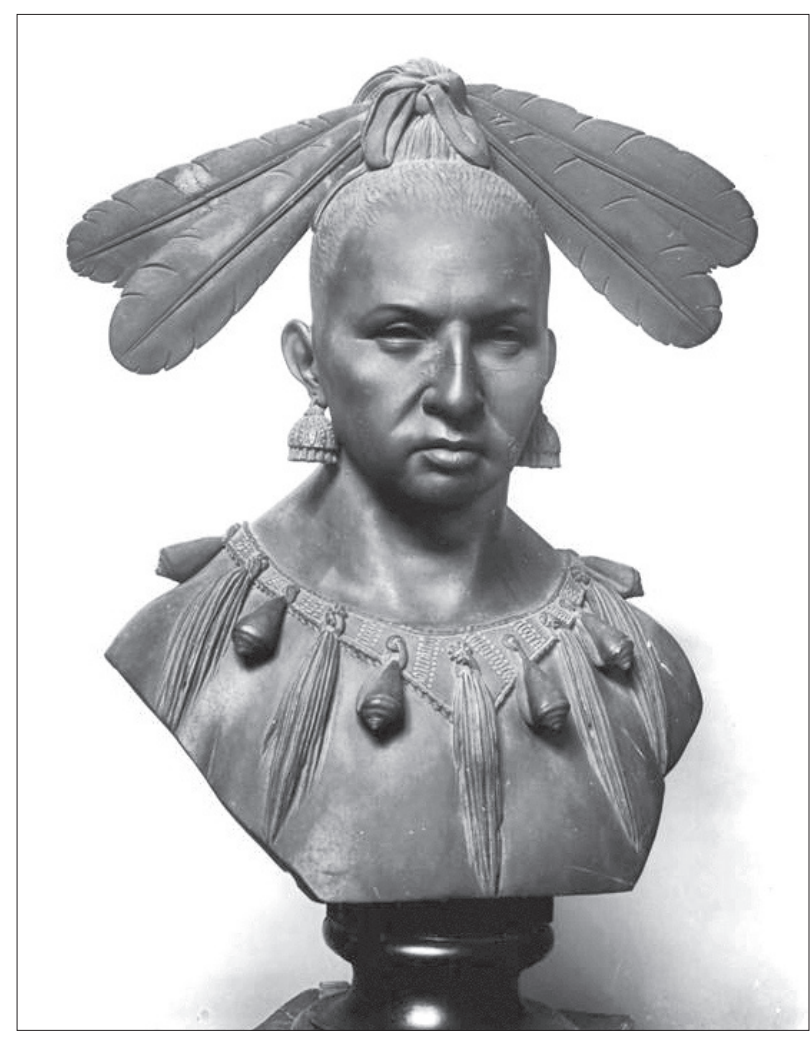

Figura 4. Ferdinand August Pettrich, Busto de un guerrero de la tribu Sauks-Foxes, yeso patinado, Vaticano, Pontificio Museo MissionarioEtnologico. Foto: Luciano Migliaccio.

El color aparentemente inspirado por la pintura de la cerámica griega arcaica (Edenheiser; Nielsen, 2013), sea talvez en sintonía con la interpretación de la policromía en la arquitectura de la antigüedad iniciada por Jacob Ignaz Hittorff. No parece fuera de lugar especular que Pettrich, ya durante su estada en Brasil, estuviese pensando en un museo dedicado a ilustrar las fisionomías, la vida y las costumbres de los nativos de América, tal como se acabó realizando más tarde en el Palacio Laterano en Roma gracias al mecenazgo del papa Pio IX.

En Brasil el escultor fue condecorado con las Ordenes de la Rosa y de Cristo y fue nombrado miembro del IHGB. Sin embargo, la hostilidad del poderoso Paulo Barbosa, ministro de la Casa Imperial, y tal vez más aún la falta de encargos públicos convenciera al escultor a procurar nuevamente la protección de la corte del papa.
Desde noviembre de 1856 el nuncio papal en Rio de Janeiro, monseñor Marino Marini, informara a la Secretaria del Estado del deseo del artista de "ver guardados en la capital del mundo los últimos vestigios de un pueblo que estaba por desaparecer" (Marini apud Dalla Torre, 1940, p. 75). Zarpando entonces de Rio en setiembre de 1857 Pettrich llegó a Southampton, en Inglaterra, donde demoró varios meses tratando de organizar una exposición de sus obras de tema amerindio en Londres. Llegó en Roma en mayo de 1858 y luego ofreció al papa Pío IX "este museo que, en la opinión de los más celebrados escultores de Europa y de América, puede decirse único de su género" (Pettrich apud Dalla Torre, 1940, p. 86).

La colección de esculturas fue aceptada por el pontífice, siendo colocada en la galería del Palacio Lateranense (Edenheiser; Nielsen, 2013; Aigner; Mapelli, 2015). El propio Pío IX fue visitarla y remuneró el artista con una pensión vitalicia de 250 libras mensuales. Las fuentes de la época revelan el interés de los estudiosos y de los artistas por las obras de Pettrich. Frederich Overbeck y Peter Cornelius, líderes de los Nazarenos, en un parecer solicitado por la corte papal escribieron:

\begin{abstract}
Se reconoce en estas fisionomías, llenas de espíritu y de vigor, un pueblo dotado de disposiciones de mente y de corazón no usuales, que tuviese tenido la suerte de ser evangelizado por misionarios católicos y de experimentar la benéfica influencia de los Serenísimos Pontíices, quizás hoy formaría florecientes comunidades cristianas capaces de consolar todo corazón verdaderamente católico por las tantas pérdidas que la fe hace todo día en la vieja Europa cristiana (Overbeck; Cornelius apud Dalla Torre, 1940, p. 87).
\end{abstract}

Pettrich murió en 14 de febrero de 1872 e fue sepultado en el cementerio de la Arciconfraternita Teutonica de Roma. Su colección de esculturas de tema americano se encuentra hoy en el Museo Etnológico Misionario en Ciudad del Vaticano. En 1859 el periódico La Civiltà Cattolica publicó un texto del jesuita Antonio Bresciani intitulado "La galleria dei ritratti de' selvaggi in Laterano" (Bresciani, 1859) en que las esculturas de 
Pettrich eran consideradas como pruebas fisiognómicas de la descendencia caucasiana de los pueblos nativos americanos y, por lo tanto, de las migraciones de eses pueblos desde el Norte hacia al Sur de América y de la relación de sus culturas con aquellas del Mediterráneo. El texto no dejaba de hacer referencia a dibujos del hijo de Ferdinand Pettrich, Adolf, que retratarían jeroglíicicos pintados sobre cueros de búfalos por nativos americanos, semejantes a los egipcios y a símbolos fenicios e indo-europeos (Bresciani, 1859, 1866). El texto es una demostración de cómo las obras de Pettrich se encontraban al cruce entre etnografía y arte y como podrían ser utilizadas en función de la construcción de una arqueología americana. Su viaje a través de los Estados Unidos, Brasil y Roma es un documento de gran importancia para entender con mayor precisión la cultura de la época y las fuentes utilizadas para la formación de una nueva iconografía nacional en el contexto americano.

\section{EL MONUMENTO ECUESTRE DE DON PEDRO I EN RIO DE JANEIRO}

En los mismos años en que Pettrich dejó Brasil, el escultor francés Louis Rochet fue incumbido de ejecutar en bronce el monumento ecuestre de Dom Pedro I en la plaza hoy llamada de Tiradentes en Rio de Janeiro (Figura 5). El monumento seria realizado en París e inaugurado en 1862, pero el artista viajó a Brasil en 1857 para presentar maquetas e inspeccionar el lugar donde seria colocada su obra. Rochet obedecería a un programa iconográfico elaborado por la corte, en particular, por Manoel de Araújo

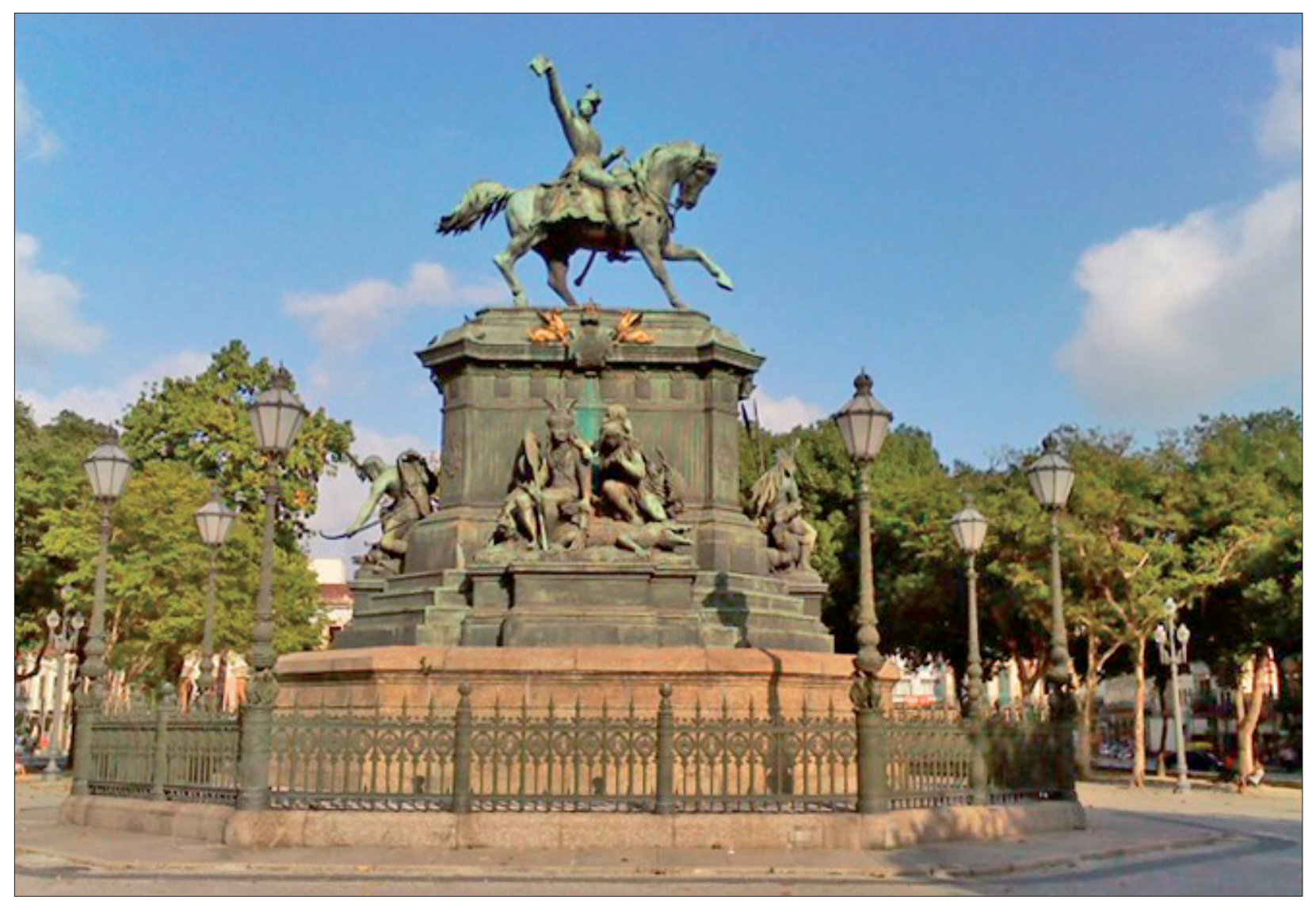

Figura 5. Louis Rochet, Monumento ecuestre de Dom Pedro I, emperador de Brasil, bronce, Rio de Janeiro, Praça Tiradentes. Foto: Luciano Migliaccio.

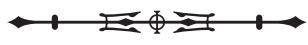


Porto-Alegre, entonces director de la Academia Imperial de Bellas Artes. Sobre un elevado basamento el fundador del imperio cabalga levantando en su derecha la constitución, como siendo soberano constitucional y héroe militar libertador, casi un nuevo Napoleón de América. Ninguna referencia a su pasado de príncipe heredero de Portugal. El caballo es dotado de un movimiento extraordinario, fruto de conocimiento anatómico fuera de lo común. Parece hincar sus patas en el suelo, en cuanto vuelve hacia el lado, girando rápidamente la cabeza. La postura de D. Pedro, levantándose en los estribos parece emular a la furia del jinete en el mismo instante en que le pone el freno. El antiguo tema de la mano del príncipe que modera y gobierna segundo su voluntad la fuerza del animal, como las corrientes que agitan el curso de la historia, es representado con un nuevo abordaje naturalista y científico. Pueden notarse recuerdos del monumento a Federico el Grande de Cristian Rauch en Berlin y tal vez de aquel de Emanuele Filiberto de Saboya de Carlo Marocchetti en Turin.

Sin embargo, lo más desconcertante dese conjunto son los grupos de indígenas circundando la base (Figura 6). Indiferentes a la presencia del emperador, estos colosos amerindios llenos de vigor clavan sus ojos en el espectador, con la mirada orgullosa e interrogativa del hombre de la selva. Parecen estar perfectamente a gusto entre los tucanes, cocodrilos, tortugas y tamandúas de medida descomunal que despuntan entre las hojas de los bananos y la intricada floresta de bronce. Se van agrupando en familias o, con sus arcos, cazan una presa invisible; descansan apoyándose en trofeos de armas, plantas y animales, como en tronos de soberanos bárbaros. Con seguridad, no faltaban ejemplos de monumentos de soberanos europeos acompañados de grupos de figuras exóticas. Los grupos de indios representan los ríos principales de Brasily remeten, por lo tanto, al motivo triunfal de la fuente de Bernini, en Piazza Navona en Roma. Al mismo tiempo, representan la unidad territorial de Brasil garantida por la monarquía, como en los aparatos para la coronación de Don Pedro II, realizados por Porto-Alegre, en 1841.

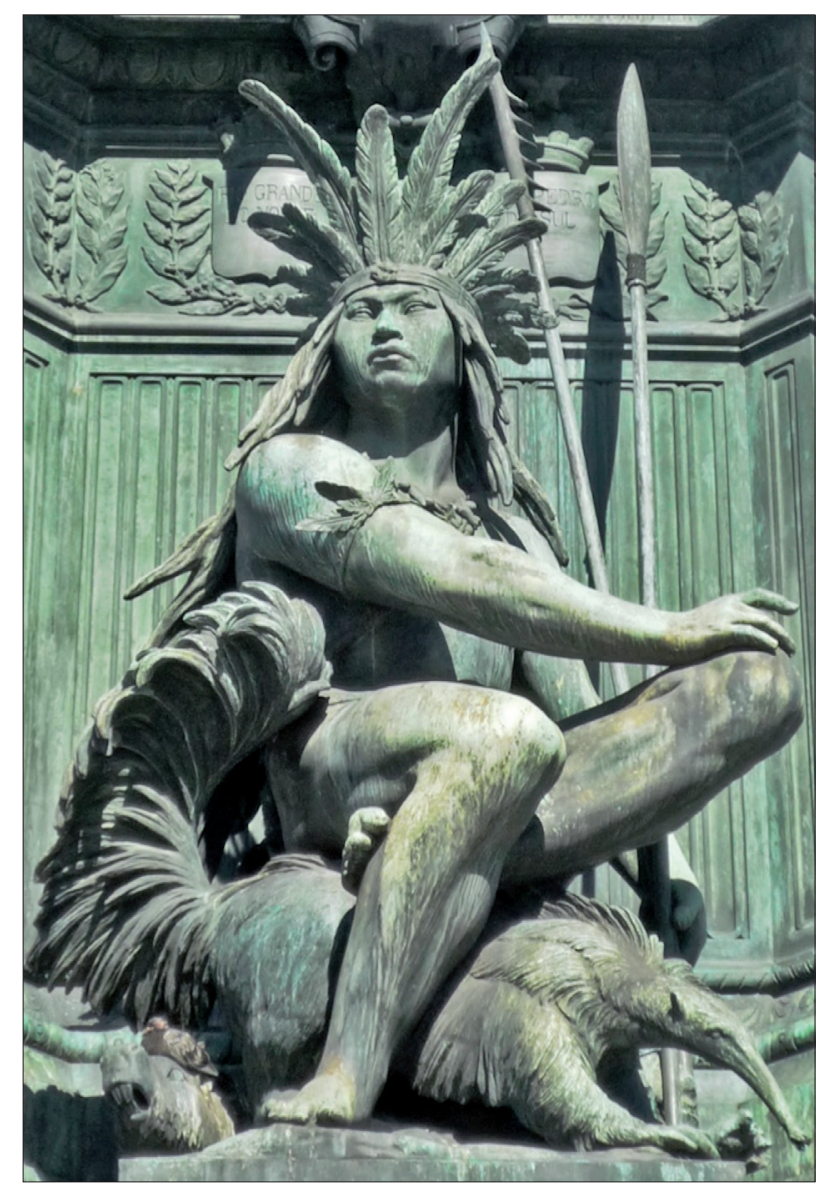

Figura 6. Louis Rochet, El Rio San Francisco, maqueta em yeso para el monumento ecuestre de Dom Pedro I, emperador de Brasil, Rio de Janeiro, Museu Histórico Nacional. Foto: Luciano Migliaccio.

En el monumento de Rio de Janeiro, sin embargo, aparece una diferente concepción histórica. Los héroes indígenas aluden a la sociedad familiar y tribal descrita en los textos de los primeros etnógrafos y arqueólogos; no están solo representando el triunfo del Imperio, o su unidad: sino representan la vida social de los indios y se justifican en una perspectiva de progreso, de la cual el Imperio, con su constitución, es la realización última. Vistiéndose con su manto y con un collar de plumas, a la manera de los caciques indígenas, los emperadores de Brasil también revindicaban para si la herencia de los nativos: el imperio brasileño se presentaba como un estado que sintetizaba, en su sociedad civil fundada modernamente en el derecho, la

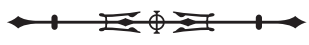


cultura indígena y la cultura de los conquistadores europeos. Desde la tribu hasta la constitución, el cuerpo y el poder del monarca son la síntesis providencial de la historia de los pueblos que forman el Imperio (Migliaccio, 2000).

El escultor francés Louis Rochet tenía un pasado de etnógrafo y estudioso de civilizaciones no europeas, en particular de la cultura china y mongol, que lo hacía particularmente adecuado para la concepción de un producto distante de los cánones de la tradición clásica y abierto a las sugerencias de la etnografía y del color local. Documentos y materiales conservados en el antiguo Musée de l'Homme, hoje no Musée du Quai Branly, y en el Institut National des Langues et Civilisations Orientales (INALCO) de París, donde se encuentra guardada la biblioteca del artista, permiten conocer mejor las fuentes figurativas de su obra. En el Cabinet d'Antropologie del Musée de l'Homme se encuentraban depositados doce estudios de indios civilizados y mestizos, y uno de un esclavo africano, realizados por Rochet durante su temporada en Brasil ${ }^{3}$. El escultor utilizó estos estudios fisiognómicos para realizar los rostros de los indios de su monumento, en cuanto que para figurar sus cuerpos, posturas y ornamentos, se sirvió seguramente de las ilustraciones de Spix y Von Martius, de Jean-Baptiste Debret, de Maximilian zu von Wied Neuwied y de los estudios de nativos norte-americanos de George Catlin, obras que podía consultar en su colección personal'4.

Dom Pedro II registró en francés en su diario cierta perplejidad en relación al realismo de la representación: "entre les groupes, ceux que je prefere sont l'Amazonie et le São Francisco, encore que ce dernier ressemble peu a un Indien du Brésil" (Dom Pedro II apud Schwarcz; Bediaga, 1999, p. 63). El emperador estaba acostumbrado a ver los indios disfrazados como héroes clásicos, vestidos de penas variadas para darles un toque exótico: ahora estaba adelante de titanos huidos del gabinete de un antropólogo - gigantes sin maneras por exceso de realismo. Sin embargo, cuando los grupos colosales de bronce fueron expuestos en el Salon de París de 1861, antes de que fuesen enviados a Brasil, el periódico L'Artiste publicó un significativo comentario:

\begin{abstract}
El señor Rochet es el primer escultor a representar a los salvajes: mal grado la falta de tradición, él desarrolló con éxito este tema difícil. Se hacía necesario temer dos obstáculos: lo feo repulsivo y lo grotesco. El artista se reveló original, sin caer en ninguno de esos dos defectos. Sus indios son de una raza exótica, carnudos, presentando apenas formas redondeadas en los rostros y en todas las partes del cuerpo, su fuerza es hedionda, su inteligencia inculta, pero son hombres y en sus rasgos, en sus poses reina una cierta dignidad altiva y casi melancólica que se ve en los pueblos que desaparecen: son naturales y sin embargo son bellos (L'Artiste apud Rochet, 1978, p. 108).
\end{abstract}

Las relaciones entre el monumento y las poéticas indigenistas que se estaban afirmando en Brasil en aquellos años resultan evidentes. Sin embargo, es posible detectar también en su programa ideas derivadas del pensamiento arqueológico que informó la acción de la Sección de Arqueología y Etnografía y de la Comisión Científica de Exploración del IHGB. En 1845, el IHGB había anunciado

\footnotetext{
3 En el Cabinet d'Antropologie del Musée de l'Homme en París se encuentraban 12 estudios de cabezas de indios e mestizos brasileros en yeso y una cabeza de bronce figurando un africano, obras ejecutadas por Louis Rochet durante su primera estadía en Brasil entre el final de 1856 y los primeros meses de 1857 (Apéndice 2). Todas las esculturas miden cerca de $27 \times 45 \times 23 \mathrm{~cm}$. Presentan apenas la cabeza y el cuello de la figura demostrando un interés exclusivo del escultor para las fisionomías. Los yesos son patinados en color de bronce dorado con una segunda patina verde tal vez posterior. Por lo que parece, Rochet retrató mestizos, caboclos e indios civilizados que era posible encontrar en Rio de Janeiro. Otras maquetas, que quedaron en el taller del artista, fueron presentadas otra vez en la Exposición Universal de Paris de 1867 (Groupe I, cl. 3, 193). A la muerte de Rochet en 1878 las maquetas originales de los grupos de indios fueron donadas al Musée d'Ethnographie du Trocadero. Em ocasión de la demolición dese edificio el gobierno francés vendió estos yesos al anticuario Robert Heyman de París, que los vendió después al brasilero Djalma Fonseca Hermes, siendo finalmente adquiridos por el gobierno de Brasil, en 7 de agosto de 1941, e destinados al Museu Histórico Nacional do Rio de Janeiro, donde todavía se encuentran.

4 Ver Apéndice 1. En los cantos de la base debían aparecer cuatro grandes luminarias en forma de palmas en bronce, pero no fueron realizadas por motivos de economía, pues Rochet incluyó más figuras en los grupos colocados nos lados largos de la base.
}

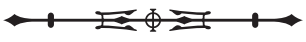


un concurso cuyo tema seria "Como se debe escribir la historia de Brasil". El ganador había sido el botánico alemán Von Martius, que había visitado el país durante mucho tiempo para realizar sus estudios sobre la flora. En su escrito el afirmaba que la historia de Brasil debía reflejar aquella de los tres grupos humanos que formaban el Imperio: africanos, indios y portugueses. El propio había dado un ejemplo de método escribiendo una disertación sobre los conceptos jurídicos y la organización social de los indígenas brasileños. Para Von Martius era necesario estudiar en profundidad las culturas africanas e indígenas destinadas a desaparecer en una nueva síntesis.

Entre 1847 e 1851, las fechas de "Primeiros Cantos" (1847) e "Últimos Cantos" (1851), de Gonçalves Dias, se definen en Brasil los temas indianistas del imaginario romántico nacionalista, derivado en gran parte del pensamiento de François-René de Chateaubriand: la valorización de la figura del primitivo, el contraste entre la corrupta cultura europea e aquella indígena destinada a dar vida a una nueva civilización al mezclarse con la primera. Los escritores indigenistas preferían proyectar en el pasado indígena el carácter original de la nueva nación, contraponiéndose a la vieja Europa en declino y también a la condición actual de los nativos. El poema "A Confederação dos Tamoyos", de Gonçalves de Magalhães, publicado en 1856, y el monumento ecuestre de Don Pedro I, encomendado en el mismo año, fueron la realización artística más acabada dese programa ideológico.

\section{CONSIDERACIONES FINALES}

La actividad de la Sección de Arqueología y Etnografía del IHGB dio origen a algunas series de imágenes que tuvieron relevancia para la construcción de una iconografía nacional en diferentes niveles. La Expedición Científica en Ceará y Amazonas produjo las ilustraciones del material arqueológico y de los artefactos indígenas recogidos por Gonçalves Dias, realizadas por el Imperial Instituto Artístico del alemán Henrique Fleiuss, publicadas en ocasión de la Exposición de Productos Industriales de 1861 en Rio de Janeiro. Produjo también los dibujos sobre la cultura material, los costumbres y las vistas del sertão cearense hechos por José dos Reis Carvalho, que quedaran inéditos y esperan hasta hoy adecuada consideración por parte de los historiadores del arte de Brasil.

Este destino diferente no fue casual. La ilustración científica relativa a las culturas nativas se encajaba en la reconstrucción del pasado nacional que la corte, a través del Instituto y de la Academia de Bellas Artes buscaba afirmar. Una visión de la historia en que el imperio se presentaba como expresión providencial, sin conflicto, de todas las culturas que lo formaban, desde la evangelización de los indios hasta a la formación del estado moderno. Por eso, la imagen etnográfica podía ser utilizada como elemento histórico en busca de la confirmación de la teoría de las migraciones y como justificativa indirecta de la decadencia de los pueblos amerindios actuales, lo que aparentemente fue hecho con las esculturas de Pettrich. Podía ser utilizada también para establecer nuevos cánones de representación épica, que innovasen la tradición europea con el elemento local, adecuado al nuevo contexto histórico, en función de propaganda. Es lo que hizo con éxito Rochet con sus colosales indios basados en moldes fisionómicos. No por acaso, la prensa republicana, por boca de Teófilo Otoni, apellidó al monumento del escultor francés de "la mentira de bronce", expresando su repudio de la visión oficial de la historia (Carvalho, 1990, p. 60).

Por motivos semejantes no fue comprendida la importancia de las imágenes de los costumbres y de la realidad del sertão creadas por Reis Carvalho. De hecho, por primera vez esas ponían a Brasil delante de nuevas contradicciones. No era solo la barbarie de la esclavitud de los africanos que separaba la nación de la modernidad plena, sino la contradicción entre el estado que se quería moderno, mas se quedaba limitado al espacio urbano, y las culturas arcaicas y mestizas que sobrevivían en el interior del país. Esta contradicción tardará mucho a ser percibida y comprendida y se expresó inclusive en la falta de interés por la representación de las costumbres locales como tema 
del arte nacional. Esta temática empezará a manifestarse solo con el nacimiento de la república federal, mas tendrá como su sujeto preferido a los inmigrantes, al mundo del campo, pasando por el género realista entonces en auge en París. Las crónicas de las vidas secas de los caboclos del sertão, dibujadas por Reis Carvalho, quedaron como una voz aislada antes que la Guerra de Canudos y los escritos de Euclides da Cunha sacudiesen las consciencias en el país.

\section{REFERENCIAS}

AIGNER, Katherine; MAPELLI, Nicola. America. Il "Museo Indiano" di Ferdinand Pettrich. In: AIGNER, Katherine; MAPELLI, Nicola (Ed.). Le Americhe: le collezioni del Museo Etnologico Vaticano. Città del Vaticano: Edizioni Museu Vaticani, 2015. p. 367-388.

AVRILON, Eva. Die Walhalla bei Regensburg: Der Beitrag der persönlichen Auswahlen zur Entstehung einer Nationalidentität. Nordestedt: Grin Verlag, 2010.

BOPP, Franz. Vergleichende Grammatik des Sanskrit, Zend, Griechischen, Lateinischen, Litthauischen, Gothischen und Deutschen. Berlin: F. Dümmler, 1833-1852.

BRESCIANI, Antonio S. J. Descrizione della Galleria di statue, bassirilievi e busti, che rappresentano i capi di varie tribù dell'America settentrionale, Opera del cav. Ferdinando Pettrich scultore collocata nella sala del Concilio del Palazzo Pontifício nel Laterano. In: BRESCIANI, Antonio S. J. Opere del p. Antonio Bresciani. Roma: Ufficio della Civiltà Cattolica; Torino: Pietro di G. Marietti, 1866. v. 5, p. 336-346.

BRESCIANI, Antonio S. J. La galleria dei ritratti de' selvaggi in Laterano. La Civiltà Cattolica, Roma, anno X, serie IV, v. 1, p. 540-549, 1859.

BUGATTO, G. Le statue indiane del Museo Missionário Etnológico Lateranense e il loro autore. L'Illustrazione Vaticana, v. 2, fasc. I, p. 33-38, 1931.

CARVALHO, José Murilo de. A formação das almas: o imaginário da República no Brasil. São Paulo: Companhia das Letras, 1990.
DALLA TORRE, Paolo. Le plastiche a soggetto indigeno nordamericano del Pettrich nel Pontificio Museo Etnologico Missionario: vicende e significato di una raccolta romana dell'Ottocento. Ciudad del Vaticano: Tipografia Poliglotta Vaticana, 1940. 96 p. (Annali Lateranensi, v. 4).

DIAS, Antônio Gonçalves. Diccionario da lingua Tupy, chamada Lingua Geral dos indigenas do Brazil. Leipzig: Brockhaus, 1858.

DIAS, Antônio Gonçalves. Os Timbiras. Leipzig: Brockhaus, 1857.

DIAS, Antônio Gonçalves. Últimos Cantos. Rio de Janeiro: Typographia de F. de Paula Brito, 1851

DIAS, Antônio Gonçalves. Primeiros Cantos. Rio de Janeiro: Laemmert, 1847.

EDENHEISER, Iris; NIELSEN, Astrid (Ed.). Tecumseh, Keokuk, Black Hawk: Indianerbildnisse in Zeiten von Verträgen und Vertreibung. Portrayals of Native Americans in Times of Treatise and Removal. Catálogo da exposição, Staatlichen Ethnographischen Sammlungen in Albertinum Dresden, Dresden, Arnoldsche, 2013.

GELLER, Hans. Franz und Ferdinand Pettrich: Zwei Sachsische Bildhauer aus der Zeit des Klassizismus. Leipzig: W. Hesse, 1955.

GONÇALVES DE MAGALHÃES, Domingos José. A Confederação dos Tamoyos: poema por Domingos José Gonçalves de Magalhães. Rio de Janeiro: Paula Brito, 1856

MIGLIACCIO, L. Mostra do redescobrimento: arte do século XIX - 19th-Century Art. 1. ed. São Paulo: Fundação Bienal de São Paulo, 2000. 224 p.

NOACK, Franz. Das deutschtum in Rom seit dem Ausgang des Mittelalters. Berlin/Leipzig: Deutsche Verlagsanstalt, 1927.

PINASSI, Maria Orlanda. Três devotos, uma fé, nenhum milagre: um estudo da Revista Niterói, 1836. São Paulo: Editora Unesp, 1998.

ROCHET, Auguste. Louis Rochet: sculpteur sinologue, 1813-1878. Paris: Editions André Bonne, 1978.

SCHWARCZ, Lilia Moritz; BEDIAGA, Begonha (Org.). Diário do Imperador D. Pedro II: 1840-1891. Petrópolis: Museu Imperial, 1999. 
Apéndice 1. Transcripción parcial del catálogo de los libros de antropología, etnografía, viajes, bellas artes, lénguas y literatura china, manchu y mongólprocedentes de la biblioteca de los Señores Hermanos Rochet redigido después de la muerte de Louis Rochet, para laventa realizada en 14 de mayo de1878 en Paris.

Catalogue des livres sur l'anthropologie, l'ethnographie, les voyages, les Beaux-Arts, les langues et la literature chinoise, mandchoue e mongole... provenant de la bibliotheque de MM. Rochet fréres aprés le décès de Louis Rochet. Vente 14/5/1878, Maison Silvestre, Rue des Bons-Enfants, 28, Paris, Ernest Leroux, 1878.

p. VI - La partie relative a l'Amerique et aux races sauvages a sourtout une veritable importance. C'est que en effet pour le monument de Dom Pedro mm. Rochet, malgré deux voyages successifs qu'ils firent au Brésil, jugerent que, pour produire une oeuvre conscienceuse d'art et de ethnografie il leur etait nécessaire d'etudier toutes les publications artistiques que les voyageurs et les savants ont laissé sur l'Amérique.

Dans cette série, nous trouvons les magnifiques études du peintre français Debret en trois volumes in-folio, l'ouvrage le plus complet qu'on ait fait sur le Brésil, et Wied-Neuwied et Rugendas, et les beaux portraits de Choris reproduisant les traits de peuples au jour d'hui disparus de la Californie, et la superbe Galerie Americaine, collection de figures de tous les anciens chefs indigenes qui ont traité avec les États-Unis et Catlin et Bodmer, ouvrages devenues rares et dont la valeur devient chaque jour plus inestimable, puisque chaque jour la disparition des races qu'ils decrivent rend impossibles des publications analogues.

L. Choris, Voyage pittoresque autour du monde, avec des portraits des sauvages d'Amérique, d'Asie, d'Afrique et des îles du grand Ocean, des paysages..., Paris, 1822.

History of the Indian tribes of North América, with biographical sketches and anecdotes of the principal chiefs embellished with one hundred and twenty portraits from the Indian Gallery in the Department of War in Washington, by Thomas L. M. Kenney and J. Hall, Philadelphia, 1838-1844, 3 voll. In folio com litografie a colori.

Transactions of the American Philosophical Society, 1, 1819, conteniendo una reseña de esa obra.

An account of the history, manners, languages of Indian nations, by Heckenwelder. Rochet poseía también la traducción francesa de ese libro, publicada en París, en 1822.

Geo Catlin, Letters and notes of the manners, customs and conditions of the North American Indians, New York, 1842.

Catlin's North American Indian Portfolio, Hunting scenes and amusements of the Rocky Mountains and prairies of America, London, 1844.

Felix de Azara, Essai sur l'histoire naturelle des quadrúpedes de la province du Paraguay. Traduction sur le manuscrit inédit par M. Moreau Saint-Mery, Paris, 1801.

F. Pyrard, Voyage au Brésil corrige et augmentée par M. Duval, Paris, 1679.

Johann Nieuhof, Gedenkweerdige Brasiliense-Zee en Lant-Reize, Amsterdam, 1682.

F. Froger, Relation d'un voyage fait en 1695, 1696 et 1697 aux Côtes d'Afrique, Detroit de Magelan, Brésil, Cayenne et Isles Antilles, par une esquadre de vasseaux du Roi commandé par Monsieur de Gennes, Paris, Nicolas Le Gras, 1699.

Georg Heinrich von Langsdorff, Voyages and travels in various parts of the world, during the years 1803, 1804, 1805, 1806 and 1807, v. 2, London, 1813.

Maximilian Wied-Neuwied, Reise durch Brasilien in den Jahren 1816 bis 1817, Frankfurt, 1820-21; y traducción francesa, Paris, Bertrand, 1821-1822.

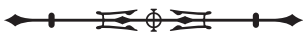


Jean-Baptiste Debret, Voyage Pictoresque et Historique au Brésil, v. 3, Paris, Didot, 1834-1839;

Johann Moritz Rugendas, Mahlerische Reise in Brasilien, Paris, Engelmann, 1835.

Hippolyte Carvalho, Études sur le Brésil au point de vue de l'émigration et du commerce français, Paris, Garnier, 1858

Charles Reybaud, Le Brésil, Paris, Guillaumin et Cie. editeurs, 1856

S. Dutot, France et Brésil, Paris, Garnier, 1859.

Alphonse De Beauchamp, L'independance du Brésil, Paris, Boucher, 1824

L'Empire du Brésil a l'exposition de Vienne en 1873, Rio de Janeiro, 1873

James Henderson, A History of the Brazil, London, Longman, 1821.

Almanak Laemmert do Rio de Janeiro, 1861 e 1862. 
Apéndice 2. Transcripción parcial del catálogo de las esculturas, maquetas, pinturas, objetos de arte y otro material existente en el taller de Louis Rochet redigido después de la muerte del artista para la venta realizada en 4 de junio de 1878 en Paris.

Catalogue des sculptures, études, tableaux, objets d'art etc. materiel garnissant l'atelier de mm. Rochet fréres et aprés le décès de $\mathrm{m}$. Louis Rochet par Horsin Leon.

Vente Rue des Trois-Bornes, 5 (atelier Rochet), 4/6/1878, Paris 1878.

p. 15 Douze Têtes de Cabocles ou Indiens Civilisées. Études anthropologiques faites d'aprés nature, au Brésil, pour servir a l'execution des groupes d'indigenes decorant le monument de l'independence bresilienne.

n. 51 Tapir. Étude fait au Brésil, d'aprés nature

n. 52 Cabocle de Canta-galla, province de Rio de Janeiro. Couché sur le dos, il tire de l'arc avec sés pieds.

n. 53 Martinho Caramuru de Santarém (Amazonie). Ce personnage avait des tatuages sur la poitrine et portait suspendus a ses oreilles des especes de guirlandes.

n. 58 Jeune Botocudo. Il ne porte pás encore la botoque à la lévre inferieur.

n. 79 Environ 30 litografies noires et coloriées. Portrait d'indiens provenant de la publication de Spix et Martius.

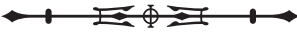

